\title{
Pre-formed urease activity of Helicobacter pylori as determined by a viable cell count technique-clinical implications
}

\author{
H. X. XIA, C. T. KEANE and C. A. O'MORAIN*
}

Department of Clinical Microbiology, St James's Hospital and ${ }^{*}$ Department of Gastroenterology, Meath/Adelaide Hospitals, Trinity College, Dublin, Ireland

\begin{abstract}
Summary. The pre-formed urease activity of three NCTC reference strains and five clinical isolates of Helicobacter pylori was determined at room temperature $\left(21^{\circ} \mathrm{C}\right)$ and $37^{\circ} \mathrm{C}$ by a viable cell count technique with a conventional urea slope test (Christensen's agar) as well as the commercial CLO-test. The urease activity of two gastroduodenal commensals, Proteus mirabilis and Klebsiella pneumoniae, was also tested. $H$. pylori strains produced positive reactions with viable cell counts of $10^{6}-10^{8} \mathrm{cfu}$ within $30 \mathrm{~min}$ and with counts of $10^{3}-10^{6} \mathrm{cfu}$ within $2 \mathrm{~h}$. For some strains, smaller numbers of organisms were needed with the CLO-test than with the conventional test, and incubation of the CLO-test strips at $37^{\circ} \mathrm{C}$ slightly decreased the number of organisms required for positive results. $P$. mirabilis produced a positive result on urea slopes with an initial inoculum of $10^{7}-10^{8} \mathrm{cfu}$ at $2 \mathrm{~h}$, but no positive reaction occurred for $K$. pneumoniae at $12 \mathrm{~h}$, even with an initial inoculum of $10^{11} \mathrm{cfu}$. However, both $P$. mirabilis and $K$. pneumoniae gave a positive result after incubation for $24 \mathrm{~h}$ with initial inocula of $<10^{1} \mathrm{cfu}$ and $10^{3}-10^{4} \mathrm{cfu}$ respectively. Incubation at $37^{\circ} \mathrm{C}$ significantly reduced the inoculum size of these organisms required for a positive result after incubation for $4 \mathrm{~h}$ when tested with the slopes, but not with the CLO-test. These findings indicate that $H$. pylori possesses much greater pre-formed urease activity than $P$. mirabilis and $K$. pneumoniae. False negative results for clinical detection of $H$. pylori in gastroduodenal biopsies may be due to small numbers of organisms, especially after treatment with antimicrobial agents, and false positive results may arise from gastroduodenal commensals or contaminants.
\end{abstract}

\section{Introduction}

Helicobacter pylori, formerly Campylobacter pylori, a common pathogen of gastroduodenal diseases, possesses an unusual characteristic of rapid urea hydrolysis, forming carbon dioxide and ammonia. ${ }^{1}$ Several invasive and non-invasive methods for detecting $H$. pylori infection in gastric biopsy specimens have been developed based on this characteristic. McNulty and Wise ${ }^{2}$ developed a urease test, which has been modified and evaluated by many other investigators. ${ }^{3-11}$ Later, urea breath tests with ${ }^{13} \mathrm{C}$ - or ${ }^{14} \mathrm{C}$ labelled urea were established ${ }^{12-13}$ and the ${ }^{15} \mathrm{NH}^{+}$ excretion test was introduced. ${ }^{14}$ However, false results occur with these tests, and their practical use is controversial. ${ }^{6,15}$ The aim of this study was to determine the pre-formed urease activity of $H$. pylori, as well as Proteus mirabilis and Klebsiella pneumoniae, by a viable cell count technique, and to evaluate the CLOtest by comparing it with the conventional slope urease test.

Received 18 Oct. 1993; accepted 4 Jan. 1994

\section{Materials and methods}

\section{Bacterial strains}

The $H$. pylori strains studied were three reference strains-NCTC11637, NCTC11638 and NCTC11639 (National Collection of Type Cultures, Public Health Laboratory Service, 61 Colindale Avenue, London)-and five clinical isolates-HP92181, HP92587, HP92766, HP921052 and HP93280 -from gastric antra of dyspeptic patients. Clinical isolates of $P$. mirabilis (PM617 and PM627) and K. pneumoniae (KP620 and KP637) were also used. H. pylori strains were subcultured on chocolate agar plates (Columbia Agar Base, Lab M, Bury, with horse blood $7 \%$ ). The plates were incubated in gas jars at $37^{\circ} \mathrm{C}$ for 3 days immediately after flushing with $\mathrm{CO}_{2} . P$. mirabilis and $K$. pneumoniae isolates were subcultured on MacConkey agar plates and incubated at $37^{\circ} \mathrm{C}$ for $18 \mathrm{~h}$ before use. Colonies were identified by Gram's stain, urease, catalase and oxidase tests and the API 20E assay (API System, S. A. La Balme Les Grottes, France). 


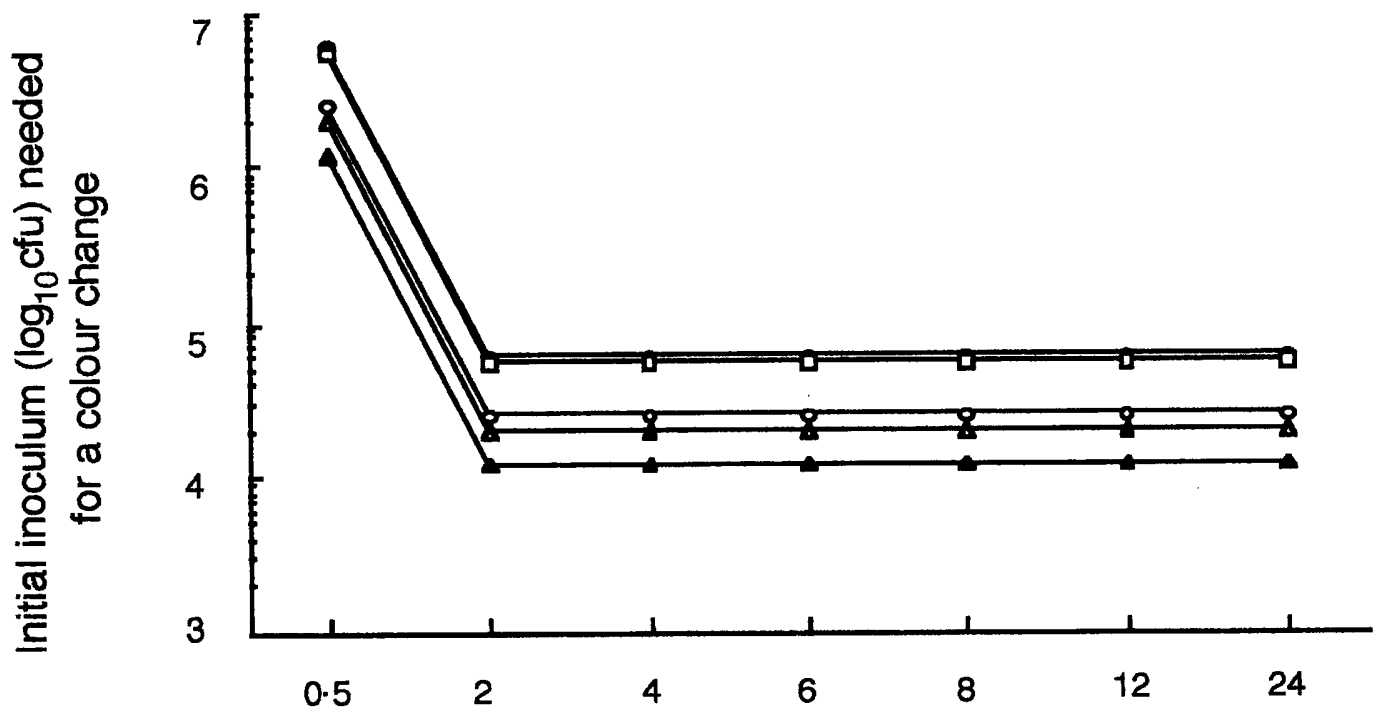

Time of incubation (h)

Fig. 1. Urease activity of $H$. pylori strains as determined by viable cell count: $-\mathrm{O}-\mathrm{NCTC1} 1637,-\mathrm{NCTC11639,}-\triangle-\mathrm{HP} 921052$, -A-HP92766, - $\square-$ HP92587.

Table. Urease activity of $K$. pneumoniae as determined by a viable count technique with the conventional slope test and the CLO-test

\begin{tabular}{|c|c|c|c|c|}
\hline \multirow{3}{*}{$\begin{array}{l}\text { Incubation time } \\
\text { (h) }\end{array}$} & \multicolumn{4}{|c|}{$\begin{array}{l}\text { Number of organisms of strain KP637 } \\
\text { required to give a colour change }\end{array}$} \\
\hline & \multicolumn{2}{|c|}{ Slope test } & \multicolumn{2}{|c|}{ CLO-test } \\
\hline & $21^{\circ} \mathrm{C}$ & $37^{\circ} \mathrm{C}$ & $21^{\circ} \mathrm{C}$ & $37^{\circ} \mathrm{C}$ \\
\hline 0.5 & $-(-)^{*}$ & $-(-)$ & - & - \\
\hline 2 & $-(-)$ & $2.5 \times 10^{9}(-)$ & $2.5 \times 10^{9}$ & $2.5 \times 10^{9}$ \\
\hline 4 & $-(-)$ & $2.5 \times 10^{9}(-)$ & $2.5 \times 10^{9}$ & $2.5 \times 10^{9}$ \\
\hline 6 & $-(-)$ & $2.5 \times 10^{9}(-)$ & $2.5 \times 10^{9}$ & $2.5 \times 10^{9}$ \\
\hline 8 & $-(-)$ & $2.5 \times 10^{7}\left(1.4 \times 10^{7}\right)$ & $2.5 \times 10^{9}$ & $2.5 \times 10^{9}$ \\
\hline 12 & $-(-)$ & $2.5 \times 10^{7}\left(1.4 \times 10^{7}\right)$ & $2.5 \times 10^{9}$ & $2.5 \times 10^{9}$ \\
\hline 24 & $2.5 \times 10^{4}\left(1.4 \times 10^{5}\right)$ & $2 \cdot 5(1 \cdot 4)$ & $2.5 \times 10^{9}$ & $2.5 \times 10^{9}$ \\
\hline
\end{tabular}

* Numbers in parentheses are for strain KP620

- , Negative test result.

\section{Urease test}

The bacterial cultures of $H$. pylori, P. mirabilis and $K$. pneumoniae (strains NCTC 11637, NCTC11639, HP92587, HP92766, HP921052, PM617, PM627, KP620 and KP637) were suspended in $5 \mathrm{ml}$ of sterile distilled water to yield a turbidity of McFarland Standard No. 2-3. The suspensions were then diluted in 100-fold steps to $10^{10}$. One hundred $\mu$ l of each dilution was placed on paired urea slopes (Christensen's agar) and spread on chocolate agar plates or MacConkey agar plates. One pair of slopes was incubated at room temperature $\left(21^{\circ} \mathrm{C}\right)$ and the remainder at $37^{\circ} \mathrm{C}$. Slopes were examined after $30 \mathrm{~min}$, $2,4,6,8,12$ and $24 \mathrm{~h}$ and tests were recorded as positive when the yellow colour changed to pink in the area of the inoculum. Viable counts were made from the plate cultures after incubation for 5 days for $H$. pylori and $18 \mathrm{~h}$ for $P$. mirabilis and $K$. pneumoniae.

\section{Comparison of CLO-test with conventional test}

The reference strains, NCTC11638 and NCTC11639, and clinical isolates of $H$. pylori, $P$. mirabilis and $K$. pneumoniae HP92181, HP93280, PM617 and KP637, were used in the comparative tests. After suspension and dilution as above, $100 \mu \mathrm{l}$ of each dilution were inoculated on to the agar areas of paired CLO-test strips (Delta West Ltd, Western Australia) and urea slopes. The strips were incubated at room temperature and $37^{\circ} \mathrm{C}$ with the slopes and read at intervals as described above.

\section{Results}

Urease activity of $H$. pylori, $P$. mirabilis and $K$. pneumoniae

$H$. pylori strains produced a positive result on urea slopes with viable bacterial counts of $10^{6}-10^{7} \mathrm{cfu}$ after 


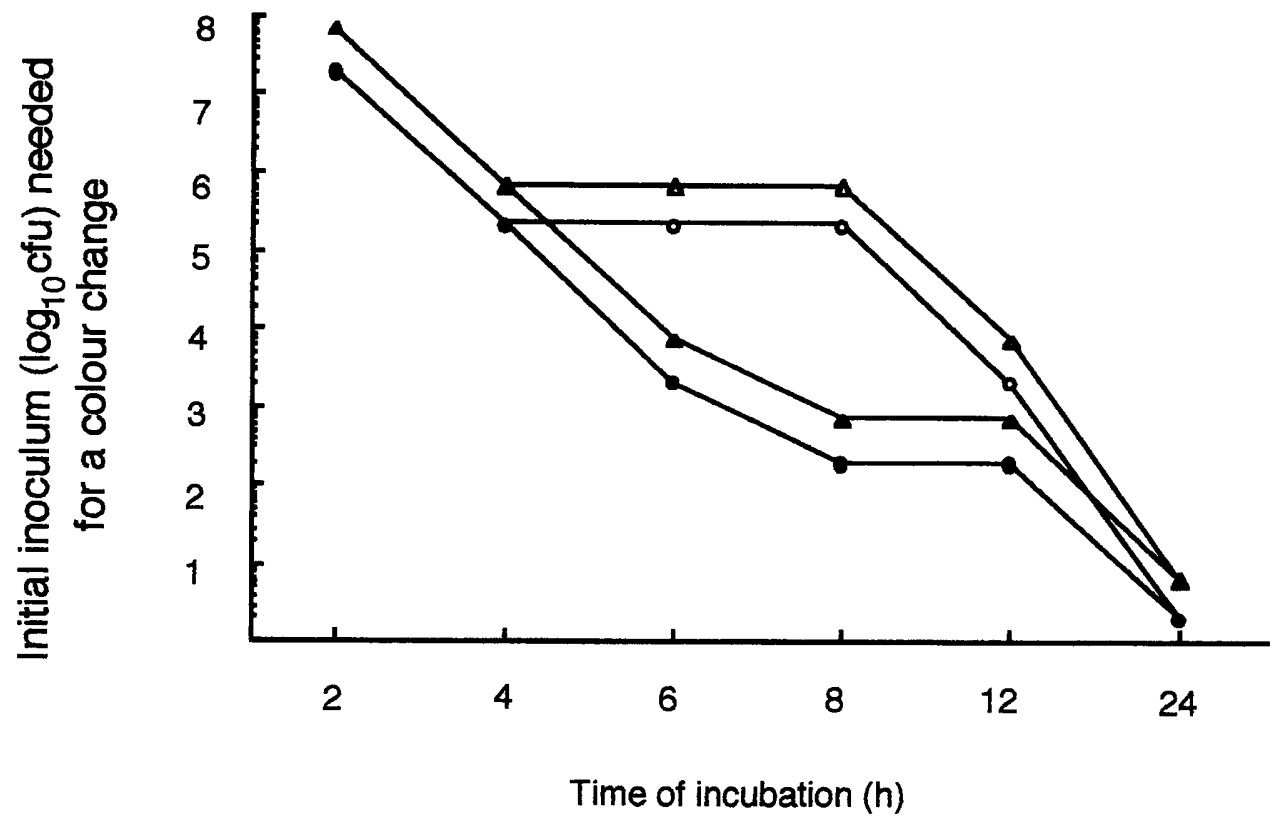

Fig. 2. Effect of temperature on urease activity of $P$. mirabilis as determined by viable cell count: $-\mathrm{O}-\mathrm{PM} 617$ at $21^{\circ} \mathrm{C},-\mathbf{O}-\mathrm{PM} 617$ at $37^{\circ} \mathrm{C},-\triangle-$ PM627 at $21^{\circ} \mathrm{C},-\Delta-$ PM627 at $37^{\circ} \mathrm{C}$.

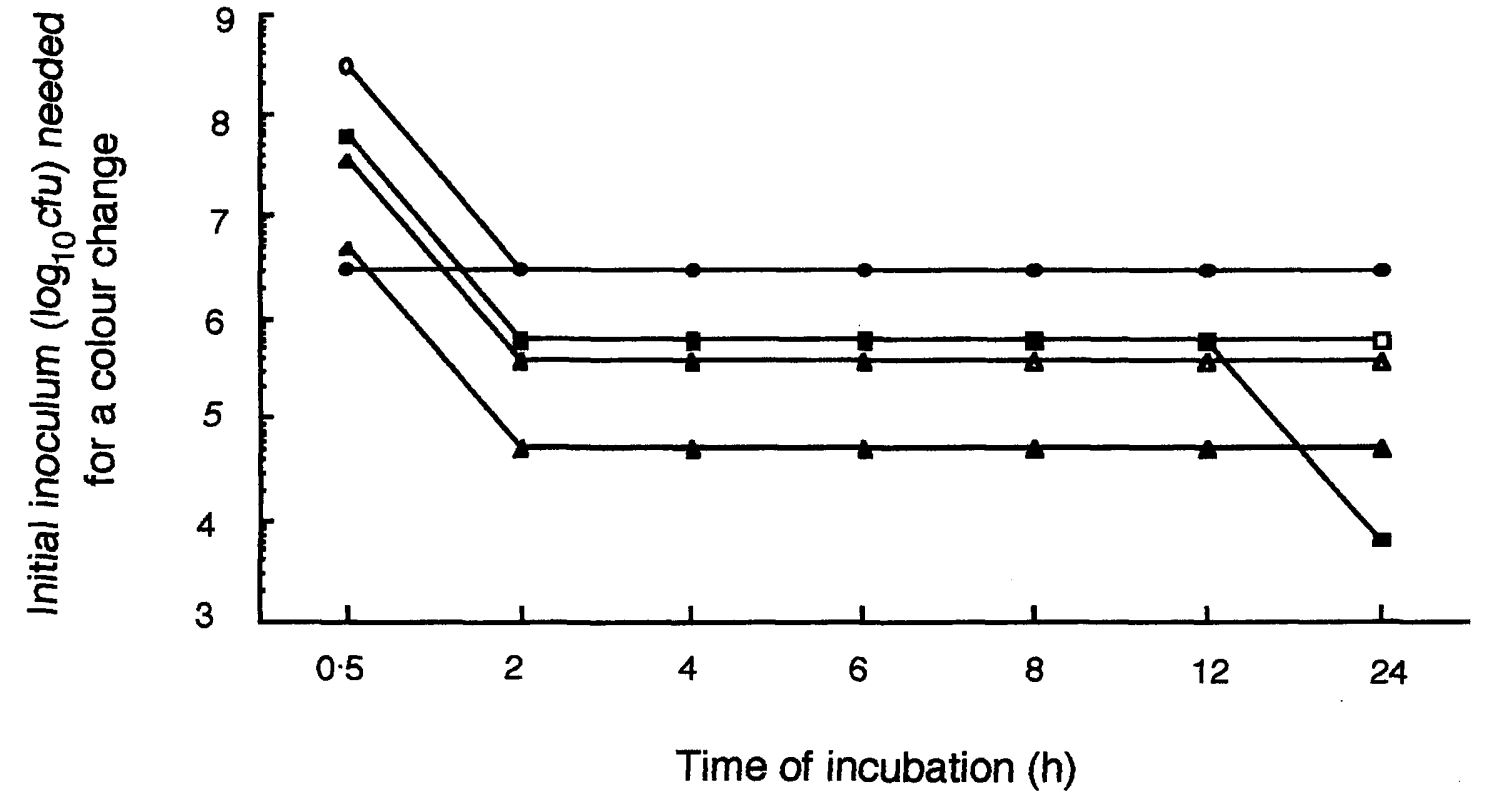

Fig. 3. Comparison of the CLO-test with the conventional urease test for $H$. pylori: - O-NCTC11638 in slope test, - - NCTC11638

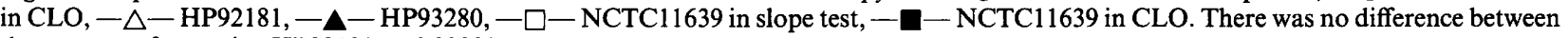
the two tests for strains HP92181 and 93280 .

incubation for $30 \mathrm{~min}$ at room temperature, but the required inoculum decreased to $10^{3}-10^{6} \mathrm{cfu}$ when incubation was prolonged to $2 \mathrm{~h}$ (figs. 1, 3 and 5). After this time, the required inoculum remained unchanged (fig. 1). For $P$. mirabilis with an inoculum of $10^{7}-10^{8} \mathrm{cfu}$, no colour change was observed before incubation for $2 \mathrm{~h}$ at room temperature (fig. 2). $K$. pneumoniae possessed even less pre-formed urease and did not produce a positive result with an initial inoculum of $10^{11} \mathrm{cfu}$ after $12 \mathrm{~h}$ at room temperature (table). However, both P. mirabilis and K. pneumoniae gave positive results at $24 \mathrm{~h}$ with initial inocula of
$<10^{1} \mathrm{cfu}$ and $10^{3}-10^{4} \mathrm{cfu}$, respectively (fig. 2 and table).

\section{Comparison of CLO-test with conventional test}

Smaller inocula of two of four $H$. pylori strains produced positive results with the modified CLO-test (fig. 3), but this was not so for P. mirabilis and K. pneumoniae (fig. 4 and table).

Incubation at $37^{\circ} \mathrm{C}$ made no difference for $H$. pylori with the conventional urease test (data not shown), but two of the four strains required a lower inoculum 


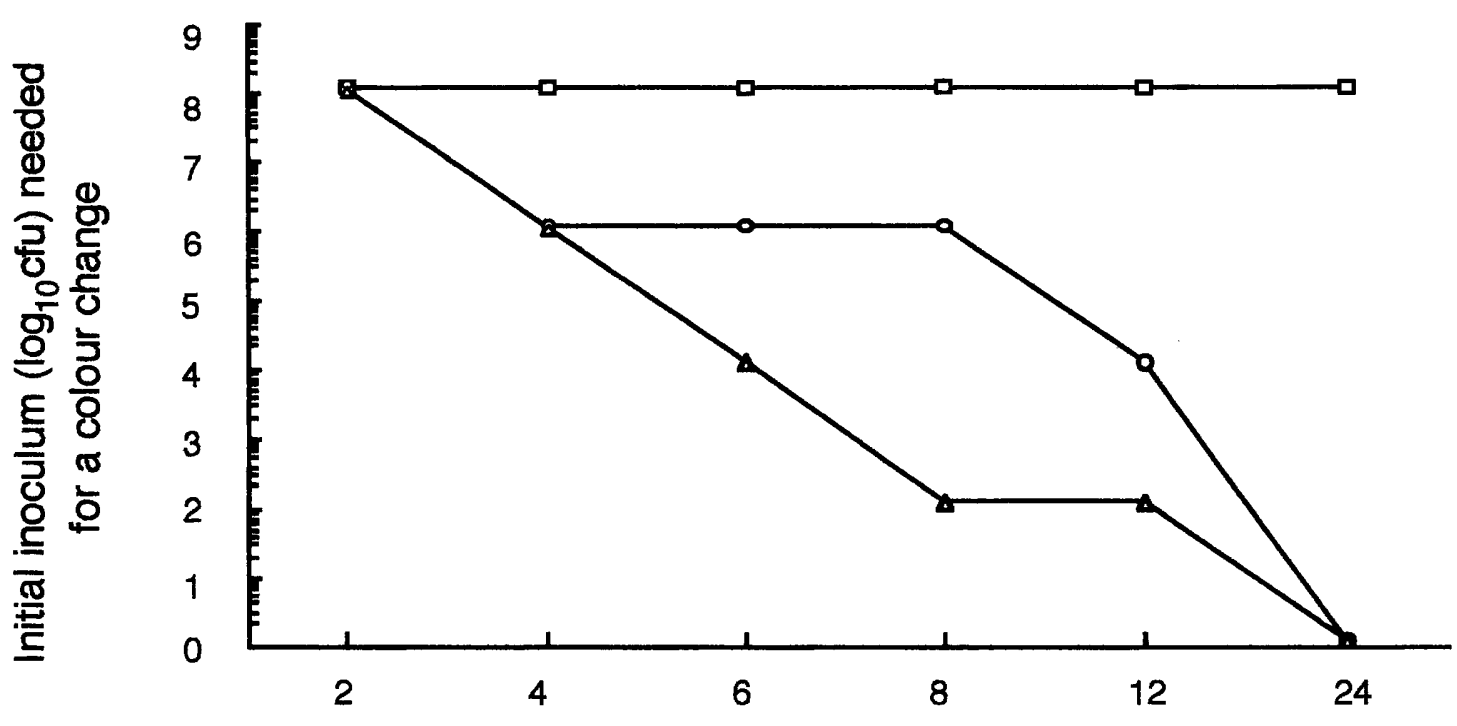

Time of incubation (h)

Fig. 4. Comparison of the CLO-test with the conventional urease test for $P$. mirabilis $\mathrm{PM} 617:-\mathrm{O}-$ at $21^{\circ} \mathrm{C}$ and $-\triangle-$ at $37^{\circ} \mathrm{C}$ in the slope test, - $\square-$ with the CLO-test. There was no difference between the results of the CLO test at the two temperatures.

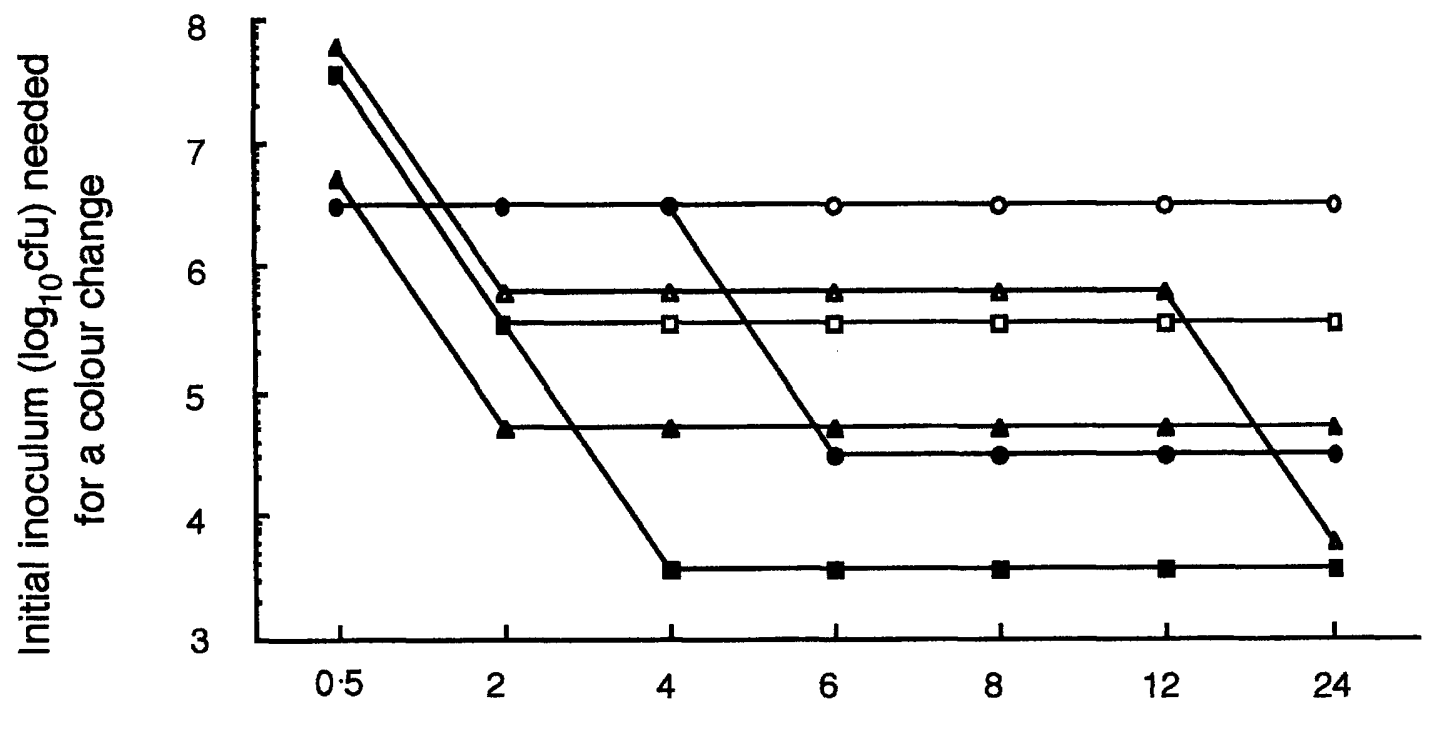

Time of incubation (h)

Fig. 5. Effect of incubation temperature on urease activity of $H$. pylori in the CLO-test: $-\mathrm{O}-\mathrm{NCTC} 11638$ at $21^{\circ} \mathrm{C},-\mathrm{O}-\mathrm{NCTC} 11638$ at $37^{\circ} \mathrm{C},-\square-\mathrm{HP} 92181$ at $21^{\circ} \mathrm{C},-\square-\mathrm{HP} 92181$ at $37^{\circ} \mathrm{C},-\triangle-\mathrm{NCTC1} 1639,-\Delta-\mathrm{HP} 93280$. There was no difference between the results obtained with strains NCTC11639 and HP93280.

with the CLO-test (fig. 5). However, for $P$. mirabilis and $K$. pneumoniae, incubation at $37^{\circ} \mathrm{C}$ significantly reduced the inoculum required for a positive result after incubation for $4 \mathrm{~h}$ with the conventional urease test, but not with the CLO-test (figs. 2, 4 and table).

\section{Discussion}

The present study showed that at least $10^{3}$ bacterial cells of $H$. pylori were required for a positive urease reaction in the CLO-test (fig. 5). However, most strains gave a positive result with an inoculum of $<10^{6} \mathrm{cfu}$.

The human gastric mucosa may become colonised with various bacterial species, ${ }^{16}$ including urease- positive bacteria other than $H$. pylori.$^{15}$ It is suggested that the urease of $H$. pylori can be distinguished from that produced by Proteus and Klebsiella spp. by its high substrate affinity and rapid hydrolysis of urea. ${ }^{17}$ In this study, the pre-formed urease activity of $H$. pylori, which usually acted within $2 \mathrm{~h}$ in the conventional urease medium, was found to be more than 100 times greater than that of $P$. mirabilis and 10000 times more than that of $K$. pneumoniae in terms of initial inoculum requirement.

The observations in the present study provide further evidence for the high specificity (86-100\%) and sensitivity (59-100\%) of urease tests in detecting $H$. pylori infection in gastric biopsy specimens. ${ }^{2-4,8-11}$ 
It is unlikely that $P$. mirabilis and $K$. pneumoniae would reach the critical concentration of $10^{7}-10^{10} \mathrm{cfu}$ in gastroduodenal specimens. In patients infected with Enterobacteriaceae, the colonising concentration in gastric mucosa was only $2 \times 10^{2}-2 \times 10^{4}$ cfu per gastric specimen. ${ }^{16,18}$ However, Khulusi et al. have shown that, in untreated patients with duodenal ulcer or gastritis, the density of $H$. pylori infection in the gastric antrum and body is as high as $(1 \cdot 3-6.9) \times 10^{8} \mathrm{cfu} / \mathrm{g}$ of tissue. ${ }^{19}$ After antimicrobial therapy, $H$. pylori can be cultured from antral biopsies at concentrations of $10^{5} \mathrm{cfu} / \mathrm{g}$ of mucosa. ${ }^{20}$ Since gastroduodenal biopsy specimens average $c .0 .02 \mathrm{~g}$ (authors' observation), a concentration of $H$. pylori in gastric mucosa is at least $2.7 \times 10^{6}$ organisms/gastric specimen for most infected, but untreated patients, and for treated patients, the concentration can still reach $2 \times 10^{3}$ organisms/ specimen.

The urease tests must be performed carefully and the results interpreted cautiously. Firstly, although most $H$. pylori strains produce positive results at $2 \mathrm{~h}$, an incubation time of $>4 \mathrm{~h}$, and up to $24 \mathrm{~h}$, may be required for a few strains (fig. 5). To avoid overgrowth of urease-positive gastric commensals or contaminants, bacteriostatic or bactericidal agents should be included in the reaction media if prolonged incubation is expected. This principle has been applied to the

\section{References}

1. Langenberg M-L, Tytgat GNJ, Schipper MEI, Rietra PJGM, Zanen HC. Campylobacter-like organisms in the stomach of patients and healthy individuals. Lancet 1984; 1: 1348.

2. McNulty CAM, Wise R. Rapid diagnosis of Campylobacterassociated gastritis. Lancet 1985; 1 : 1443-1444.

3. Morris A, McIntyre D, Rose T, Nicholson G. Rapid diagnosis of Campylobacter pyloridis infection. Lancet 1986; 1: 149.

4. Marshall BJ, Warren JR, Francis GJ, Langton SR, Goodwin CS, Blincow ED. Rapid urease test in the management of Campylobacter pyloridis-associated gastritis. Am J Gastroenterol 1987; 82: 200-210.

5. Borromeo M, Lambert JR, Pinkard KJ. Evaluation of "CLOtest" to detect Campylobacter pyloridis in gastric mucosa. $J$ Clin Pathol 1987; 40: 462-463.

6. Das SS, Bain LA, Karim QN, Coelho LG, Baron JH. Rapid diagnosis of Campylobacter pyloridis infection. $J$ Clin Pathol 1987; 40: 701-702.

7. Vaira D, Holton J, Cairns S, Falzon M, Salmon P. Four hour rapid urease test (RUT) for detecting Campylobacter pylori: is it reliable enough to start treatment? J Clin Pathol 1988; 41 : 355-356.

8. Vaira D, Holton J, Cairns S et al. Urease tests for Campylobacter pylori: care in interpretation. J Clin Pathol 1988; 41: 812-813.

9. Arvind AS, Cook RS, Tabaqchali S, Farthing MJG. Oneminute endoscopy room test for Campylobacter pylori. Lancet 1988; 1: 704.

10. McNulty CAM, Dent JC, Uff JS, Gear MWL, Wilkinson SP. Detection of Campylobacter pylori by the biopsy urease test: an assessment in 1445 patients. Gut 1989; 30: 1058-1062.
CLO-test. Sensitivity and specificity may also be improved by accelerating the action of pre-formed urease of $H$. pylori, e.g., by changing the concentration of the substrate or the indicator or both, or by changing the indicator. Incubation at $37^{\circ} \mathrm{C}$ slightly increases the sensitivity for some strains (fig. 5), but it will also increase the possibility of the false positive results due to gastric commensals or contaminants that grow rapidly at $37^{\circ} \mathrm{C}$ (figs. 2,4 , and table). False negative results may occur in some situations. For example, the number of organisms in gastroduodenal biopsies will be reduced significantly (even if not fully eradicated) by antimicrobial agents or $H$. pylorisuppressing drugs. Finally, since the distribution of $H$. pylori in gastric mucosa is patchy, false negative results may occur when the biopsy specimen contains small numbers of organisms.

The urease test is simple, easy, rapid and cheap. It has high specificity and sensitivity for detecting $H$. pylori in the gastric mucosa, and is suitable for primary diagnosis in patients undergoing endoscopy. However, other methods that are not based on urease activity may be needed for some patients, especially those who have been treated already with antimicrobial agents.

We thank Mr L. English of the Department of Clinical Microbiology, St James's Hospital, Dublin, for his helpful technical advice and useful discussion.

11. Thillainayagam AV, Arvind AS, Cook RS, Harrison IG, Tabaqchali S, Farthing MJG. Diagnostic efficiency of an ultrarapid endoscopy room test for Helicobacter pylori. Gut 1991; 32: 467-469.

12. Graham DY, Klein PD, Evans DJ et al. Campylobacter pylori detected noninvasively by the ${ }^{13} \mathrm{C}$-urea breath test. Lancet 1987; 1: 1174-1177.

13. Bell GD, Weil $\mathbf{J}$, Harrison $\mathrm{G}$ et al. ${ }^{14} \mathrm{C}$-urea breath analysis, a non-invasive test for Campylobacter pylori in the stomach. Lancet 1987; 1: 1367-1368.

14. Wu JC, Liu GL, Zhang ZH et al. ${ }^{15} \mathrm{NH}^{+}$Excretion test: a new method for detection of Helicobacter pylori infection. $J$ Clin Microbiol 1992; 30: 181-184.

15. Räisänen S, Södervik H. Colonization of gastric lesions by urease-positive bacteria. Am J Clin Pathol 1989; 90: 749-750.

16. Drasar BS. The bacterial flora of the stomach. In: Rathbone BJ, Heatley RV (eds) Campylobacter pylori and gastroduodenal disease. Oxford, Blackwell Scientific Publications. 1989: 5-11.

17. Mobley HLT, Cortesia MJ, Rosenthal LE, Jones BD. Characterization of urease from Campylobacter pylori. J Clin Microbiol 1988; 26: 831-836.

18. Borriello SP, Reed PJ, Dolby JM, Barcley FE, Webster ADB. Microbial and metabolic profile of achlorhydric stomach: comparison of pernicious anaemia and hypogammaglobulinaemia. J Clin Pathol 1985; 38: 946-953.

19. Khulusi S, Mendall MA, Patel P, Levy J, Goggin PM, Northfield TC. Quantitative study of $H$. pylori infection density, urease activity and pathogenicity. Acta Gastroenterol Belg 1993; 56 Suppl: 114 (abstract).

20. Beji A, Vincent P, Darchis I, Husson MO, Cortot A, Leclerc H. Evidence of gastritis with several Helicobacter pylori strains. Lancet 1989; 2: 1402-1403. 